\title{
A HILBERT-TYPE INTEGRAL INEQUALITY IN THE WHOLE PLANE WITH THE HOMOGENEOUS KERNEL
}

\author{
AIZHEN WANG AND BICHENG YANG
}

Abstract. By using the way of weight functions and the technique of real analysis, a new Hilberttype integral inequality with the homogeneous kernel of degree 0 in the whole plane with the best constant factor is given. As applications, the equivalent inequalities with the best constant factors, the reverses and some particular cases are obtained.

Mathematics subject classification (2010): 26D15.

Keywords and phrases: Weight function, Hilbert-type integral inequality, homogeneous kernel, equivalent form.

\section{REFERENCES}

[1] G. H. Hardy, J. E. Littlewood, G. Pólya, Inequalities, Cambridge University Press, Cambridge, UK, 1952.

[2] D. S. Mitrinović, J. E. PEČARIĆ, A. M. FINK, Inequalities involving functions and their integrals and derivatives, Kluwer Academic Publishers, Boston, USA, 1991.

[3] B. YANG, The norm of operator and Hilbert-type inequalities, Science Press, Beijing, China, 2009.

[4] B. YANG, A survey of the study of Hilbert-type inequalities with parameters, Advances in Mathematics, vol. 38, no. 3, pp. 257-268, 2009.

[5] B. YANG, On the norm of an integral operator and applications, J. Math. Anal. Appl., 321, pp. 182192, 2006.

[6] J. XU, Hardy-Hilbert's inequalities with two parameters, Advances in Mathematics, vol. 36, no. 2, pp. 63-76, 2007.

[7] B. YANG, On the norm of a Hilbert's type linear operator and aplications, J. Math. Anal. Appl., 325, pp. 529-541, 2007.

[8] D. XIN, A Hilbert-type integral inequality wth the homogeneous kernel of zero degree, Mathematical Theory and Applications, vol. 30, no. 2, pp. 70-74, 2010.

[9] B. YANG, A Hilbert-type integral inequality with the homogenous kernel of degree 0, Journal of Shandong University (Natural Science), vol. 45, no. 2, pp. 103-106, 2010.

[10] M. Krnic, J. PeCARIC, General Hilberts and Hardys inequalities, Math. Inequal. Appl. 8, pp. 2952, 2005.

[11] I. PeRIC, P. Vukovic, Hardy-Hilberts inequalities with a general homogeneous kernel, Math. Inequl. Appl. 12, pp. 525-536, 2009.

[12] B. YAng, A new Hilbert-type inequalities, Bull. Belg. Math. Soc., vol. 13, 479-487, 2006.

[13] Z. ZENG, Z. XIE, On a new Hilbert-type integral inequality with the homogeneous kernel of degree 0 and the integral in whole plane, Journal of Inequalities and Applications, Vol. 2010, Article ID 256796, 9 pages.

[14] B. HE, B. YANG, On a Hilbert-type integral inequality with the homogeneous kernel of 0-degree and the hypergeometric function, Mathematics Practice and Theory, vol. 40, no. 18, 203-211, 2010.

[15] B. YANG, A reverse Hilbert-type integral inequality with some parameters, Journal of Xinxiang University (Natural Science Edition), vol. 27, no. 6, 1-4, 2010.

[16] J. Kuang, Applied inequalities, Shangdong Science and Technology Press, Jinan, China, 2004.

[17] J. KuANG, Introduction to Real Analysis, Hunan Education Press, Changsha, China, 1996. 